\title{
Chemoselective $N$-Nitrosation of Secondary Amines under Mild and Heterogeneous Conditions
}

\author{
Mohammad Ali Zolfigol, A Aash Ghorbani Choghamarani, Abolfaul Tayian-Nasab, \\ Hassan Keypour, and Sadegh Salehzadeh \\ ('hemisty Department, ('ollege of Sience, Bu-Ali Sina Lniversity, Hamadan 65174, Iran \\ Received Vovember 18,2002
}

Key Words : A-Nitosation, Secondary amines. Helerogeneous conditions, N-Nitroso amines

i-Nitrosation of amines is an important and wellestablished reaction in organic synthesis.' The most general reagent is nitrous acid, generated from sodium nitrite and mineral acid in water or in mixed alcolol-water solvents. ${ }^{2}$ Other nitrosating agents. such as Fremy's salt. ${ }^{2}$ bis(triphenylphosphine)nitrogen( $1+$ ) nitrite ${ }^{4}$-haloamides and sodium nitrite under phase-transfer conditions. " oxyhyponitrite." dinitrogen tetroxide." solid acids and sodium nitrite have also been used." Very recently, we have demonstrated that the heterogeneous reagent systems have many advantages such as simple experimental procedures, mild reaction conditions and minimization of chemical wastes as compared to the liquid phase counterparts.., 9

Therefore. we have investigated a number of different reaction conditions based upon the in situ generation of $\mathrm{HNO}_{2}$ by relatively strong inorganic acidic salt I (i.e. $\mathrm{Al}\left(\mathrm{HSO}_{1}\right)_{3}, \mathrm{P}_{\mathrm{a}} \approx \mathrm{l}$ ) or organic acidic salts (II and III) and sodium nitrite (IV) for the nitrosation of secondary amines. We wish to report a simple. cheap and chemoselective method for the effective nitrosation of secondary amines under mild and heterogeneous conditions.

Different types of secondary amines (1) were subjected to the nitrosation reaction in the presence of a solid acid. I. II or 111. $\mathrm{NaNO}_{2}(\mathrm{IV})$ and wet $\mathrm{SiO}_{2}\left(50 \% w^{\prime}\right)$ in dichloromethane (Scheme 1). The nitrosation reactions were performed under mild and completely heterogeneous conditions at room temperature and took place with excellent yields (Table 1 ).

This present nitrosation reaction can be readily carried out by placing a solid acid. $\mathrm{NaNO}_{2}$ amine. wet $\mathrm{SiO}_{2}(50 \% w w)$ and $\mathrm{CH}_{2} \mathrm{Cl}_{2}$ into a reaction vessel and efficiently stirring the resulting heterogeneous mixture at room temperature. The 1-nitrosoamines (2) can be obtained simply by filtration and exaporation of the solvent. The results and reaction conditions are given in the Table 1.

ln order to demonstrate the chemoselectivity of this method a competitive reaction was performed between

"Corresponding atthor. lax: +98-81-8272404: e-mail: Zolfi' basulac.ir

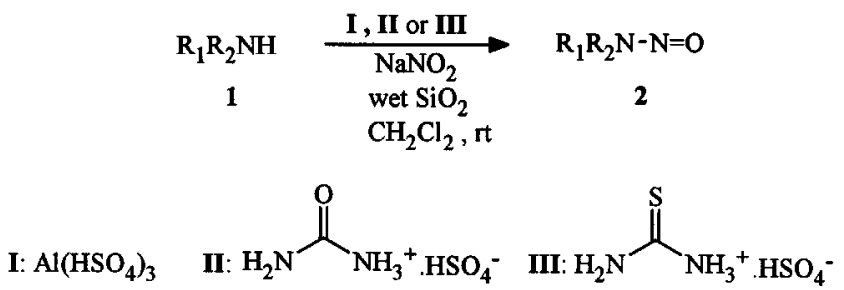

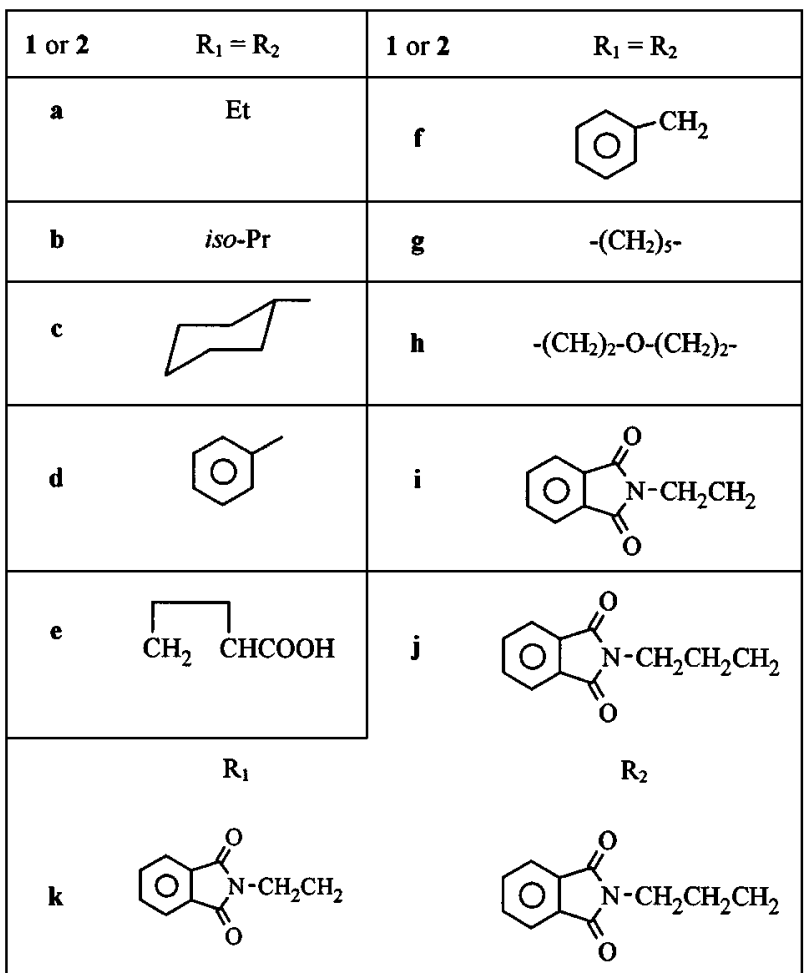

Scheme 1

dibenzy lamine (1f) and anisole. It was observed that amine nitrosation occurred exclusively whereas anisole remained intact in the reaction mixture after one hour. The nitrosation reaction of diphenylamine (1d) further showed the chemoselectivity of the method as the $A$-nitrosodiphemylamine is the only product. This system thus behaves differently from 
Table 1. Nitrosation of secondar amines (1) by a combination of solid acid (1, Il, or $\mathbf{l}$ ), $\mathrm{NaNO}_{2}(\mathbf{I V})$ and wet $\mathrm{SiO}_{2}\left(50 \% w^{\prime} \mathbf{w}^{\prime}\right)$ in dichloromethane at room temperature

\begin{tabular}{|c|c|c|c|c|c|c|c|c|}
\hline \multirow{2}{*}{ Jiנlng. } & \multirow{2}{*}{ Substrate } & \multirow{2}{*}{ Produet ${ }^{a}$} & \multicolumn{4}{|c|}{ (Reagent Sulbstrate) } & \multirow{2}{*}{$\begin{array}{c}\text { Time } \\
\text { (h) }\end{array}$} & \multirow{2}{*}{$\begin{array}{c}\text { Yield } \\
\left(0_{0}\right)\end{array}$} \\
\hline & & & I & II & III & IV & & \\
\hline 1 & 1a & $2 a^{5-.10}$ & 0.5 & - & - & 1.5 & 0.5 & 98 \\
\hline 2 & 1a & $2 a^{6-.10}$ & - & 1.5 & - & 1.5 & 0.5 & 54 \\
\hline 3 & 1a & $2 a^{5-.10}$ & - & - & 1.5 & 1.5 & 1 & 54 \\
\hline 4 & $1 \mathrm{~b}$ & $2 b^{10}$ & 0.5 & - & - & 1.5 & 0.5 & 88 \\
\hline 5 & $1 \mathrm{~b}$ & $2 b^{10}$ & - & 1.5 & - & 1.5 & 1 & 94 \\
\hline 6 & $1 \mathrm{~b}$ & $2 b^{10}$ & - & - & 1.5 & 1.5 & 1 & 96 \\
\hline 7 & 1c & $2 c^{5}$ & 0.5 & - & - & 1.5 & 0.5 & 98 \\
\hline 8 & 1c & $2 c^{5}$ & - & 1.5 & - & 1.5 & 0.5 & 9) \\
\hline 9 & 1c & $2 c^{5}$ & - & - & 1.5 & 1.5 & 0.5 & 9) \\
\hline 10 & 1d & $2 \mathrm{~d}^{2}$ & 0.5 & - & - & 1.5 & 0.5 & 99 \\
\hline 11 & $1 \mathrm{~d}$ & $2 \mathrm{~d}^{2}$ & - & 1.5 & - & 1.5 & 2 & 85 \\
\hline 12 & $1 \mathrm{~d}$ & $2 d^{2}$ & - & - & 1.5 & 1.5 & ] & 93 \\
\hline 13 & 10 & $2 e^{t}$ & 0.5 & - & - & 1.5 & ] & 86 \\
\hline 14 & 10 & $2 e^{t}$ & - & 1.5 & - & 1.5 & 2 & 78 \\
\hline 15 & 10 & $2 \mathrm{e}^{\mathrm{t}}$ & - & - & 1.5 & 1.5 & 2 & 89 \\
\hline 16 & $1 f$ & $2 \mathrm{f}^{5}$ & 0.5 & - & - & 1.5 & 0.5 & 98 \\
\hline 17 & $1 f$ & $2 \mathbf{f}^{5}$ & - & 1.5 & - & 1.5 & 0.5 & 94 \\
\hline 18 & If & $2 f^{5}$ & - & - & 1.5 & 1.5 & 1 & 98 \\
\hline 19 & $1 \mathrm{~g}$ & $2 \mathrm{~g}^{-10}$ & 0.5 & - & - & 1.5 & 0.5 & 98 \\
\hline 20 & $1 \underline{g}$ & $2 g^{-10}$ & - & 1.5 & - & 1.5 & 1.25 & 46 \\
\hline 21 & $1 g$ & $2 \mathrm{~g}^{-10}$ & - & - & 1.5 & 1.5 & 1 & 58 \\
\hline 22 & $1 h^{12}$ & $2 h^{3}$ & 0.5 & - & - & 1.5 & 0.5 & 90 \\
\hline 23 & $1 h^{13}$ & $2 h^{3}$ & - & 1.5 & - & 1.5 & 0.75 & 80 \\
\hline 24 & $1 h^{12}$ & $2 h^{3}$ & - & - & 1.5 & 1.5 & 0.75 & 99 \\
\hline 25 & $1 \mathrm{i}$ & $2 i^{8 \mathrm{si}}$ & 0.5 & - & - & 1.5 & 1.5 & 52 \\
\hline 26 & $1 \mathrm{i}$ & $2 i^{S i c}$ & - & 1.5 & - & 1.5 & 1.5 & 86 \\
\hline 27 & $1 \mathrm{i}$ & $2 i^{8 \mathrm{sic}}$ & - & - & 1.5 & 1.5 & 2.75 & 85 \\
\hline 28 & $1 j$ & $2 j^{8 c}$ & 0.5 & - & - & 1.5 & 0.75 & 68 \\
\hline 29 & $1 j$ & $2 j^{s i c}$ & - & 1.5 & - & 1.5 & 1 & 84 \\
\hline 30 & $1 \mathrm{j}$ & $2 j^{\mathrm{sic}}$ & - & - & 1.5 & 1.5 & 0.5 & 81 \\
\hline 31 & $1 \mathrm{k}$ & $2 k^{S t}$ & 0.5 & - & - & 1.5 & 1 & 48 \\
\hline 32 & $1 \mathrm{k}$ & $2 k^{S c}$ & - & 1.5 & - & 1.5 & 1 & 4.3 \\
\hline 33 & $1 \mathrm{k}$ & $2 k^{S_{i}}$ & - & - & 1.5 & 1.5 & 2 & 88 \\
\hline
\end{tabular}

"All of the isolated products are known and their spectra and physical data have been reported in the literature. "Wet $\mathrm{SiO}_{2}$ : substrate $0.2 \mathrm{~g}: 1$ mmoly. 'Isolated viclds.

some reported methods ${ }^{2}$ in that nitrosonium ion $\left(\mathrm{NO}^{\prime}\right)$ attacks the nitrogen sites of the secondary amines even where an aromatic moiety is connected directly to the nitrogen atom.

Furthermore. the chiral center of L-proline (1c) also remained intact in the course of the reaction so that $\mathrm{L}$ nitrosoproline (2c) was obtained in good vields (Table 1 . Scheme 1. Entries 13-15). L-Nitrosoproline (2e) is a precursor of mesoionic moieties in an important class of dipolar heterocyclic compounds with special properties."

Some of the amines used are very important precursors for the synthesis of symmetrical and asymmetrical tripodal tetraanines (Table 1. Entries 25-33). 1.1.3 we therefore believe that their nitroso derivatives were also very useful for the sy nthesis of special NO releasing complexes. ${ }^{\mid 4,1.5}$<smiles>O=C1c2ccccc2C(=O)N1CCNCCNCCN1C(=O)c2ccccc2C1=O</smiles>

3<smiles>[R4]CCCCCN([Y])CCN([NH])CCN1C(=O)c2ccccc2C1=O</smiles>

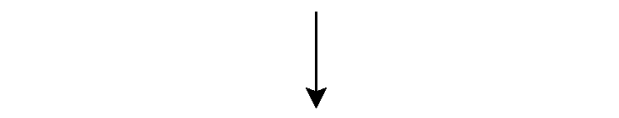<smiles>NN(CCN(N)O[Na])CCN1C(=O)c2ccccc2C1=O</smiles>

Scheme 2

Several attempts for the selective mono and dinitrosation of tetraamines (3) in order to produce its mono and dinitroso derivatives ( 4 and 5 ) were unsuccessful. This may be due to instability of these compounds in solution (Scheme 2).

The nitrosation reaction did not occur in the absence of wet $\mathrm{SiO}_{2}$. This observation suggests that the water molecule is essential for such processes. The presence of wet $\mathrm{SiO}_{2}$ thus provides an effective heterogeneous surface area for $i n$ situ generation of $\mathrm{HNO}_{2}$. It also eases the reaction work-up.

In conclusion. the cheapness and the availability of the reagents, easy and clean work-lup, chemoselectivity and high yields make this method attractive for organic chemists. This simple procedure is highly selective, and contamination by deprotection and C-nitrosation side-products is avoided.

\section{Experimental Section}

General. Chemicals were purchased from Fluka. Merck and Aldrich chemical companies. Yields refer to isolated pure products. The nitrosation products were characterized by comparison of their spectral (IR. 'H-NMR, ${ }^{13} \mathrm{C}-\mathrm{NMR}$ ). TLC and physical data with the authentic samples.

General procedure for $N$-nirosation of secondary amines. A suspension of sodium nitrite. inorganic acidic salt (The molar ratio of inorganic acidic salt and sodium ritrite to the substrate 1 was optimized as show in in Table 1). amine (1. $2 \mathrm{mmol}$ ) and wet $\mathrm{SiO}_{2}(50 \% \mathrm{w}$ w. $0.4 \mathrm{~g})$ in dichloromethane ( $4 \mathrm{ml}$ for Entries $1-24$ and $20 \mathrm{~mL}$ for Entries 25-33) was vigorously stirred magnetically at room temperature. The progress of the reaction was followed by TLC. The reaction mixture was filtered after completion of the reaction. The residue was washed with $\mathrm{CH}_{2} \mathrm{Cl}_{2}(2 \times 5 \mathrm{~mL})$. Then 
anhydrous $\mathrm{Na}_{2} \mathrm{SO}_{4}(5 \mathrm{~g})$ was added to the filtrate. and the solution was filtered after 20 minutes. The solvent was exaporated and the $\mathrm{N}$-nitroso compounds (2) were obtained (Table l). If further purification is needed. flash chromatography on silica gel [eluent : acetone/petroleum ether (10: 90)] provides pure 2 .

$N$-Nirosation of diphenyl amine (1d) with $\mathrm{Al}\left(\mathrm{HSO}_{4}\right)_{3}$ (I), $\mathrm{NaNO}_{2}$ (IV) and wet $\mathrm{SiO}_{2}$ : A typical procedure. A suspension of compound ld (0.338 g. 2 mmol). I (0.318 g l munol), wet $\mathrm{SiO}_{2}(50 \% w, \mathrm{w}, 0.4 \mathrm{~g})$ and IV $(0.4 \mathrm{l}+\mathrm{g}, 6 \mathrm{mmol})$ in dichloromethane $(4 \mathrm{~mL})$ was stirred at room temperature for 30 minutes. while the progress of the reaction was monitored by TLC. and then filtered. Anhydrous $\mathrm{Na}_{2} \mathrm{SO}_{4}(5$ g) was added to the filtrate. After 15 minutes the resulting mixture was also filtered. Dichloromethane was removed by water bath $\left(35-40^{\circ} \mathrm{C}\right)$ and simple distillation. The yield was $0.360 \mathrm{~g} .(94 \%)$ of cry stalline yellow solid (2d). mp $65-67^{\circ} \mathrm{C}$ [Lit. ${ }^{2} \operatorname{mp} 67^{\circ} \mathrm{C}$ ].

Acknowledgment. This research project has been supported by grant No. NRCI 32-296 of National Research Projects and with support of National Research Council of Islamic Republic of Iran.

\section{References}

I. (a) Williamsi, D. I. II. Sipptemen F2: $7 h_{h}$ Chemistry of Amine, Hitroso. Nitro and Related Gronps: Jolun Wiley \& Sons Lid: 1996: pp 665-682. (b) Keeler. L. K.: Williams. D. L. H. Whethods in Xitric Oxide Reseach: John Wiley \& Sons Lid.: 1996: pp 509519.

2. (a) Fumiss, B. S.: IJamatord, A. I.; Smith, P. W. G.: Tatehell. A. R. Figets Text Besot of Practicat Organic Chemistry. thl $\Gamma \mathrm{d}$.: Longman: London and New York. 1986. (b) Sheriner. R. L.: Reynold. T. L.: Fuson. C.: Curtin. D. Y.: Morrill. T. C. The Systematic Idemification of Organic componds. Gla Ed.: John Wiley and Sons: 1980: pp 220-223.

3. Castedo, I.: Rigucra, R.: Verquer, M. P. J. Chem. Soc. Chem. Commm. 1983, 301.
4. Fanning. I. C.: Keefer. L. K.: Lamy. K. J. (hom Soc. Chem. (ommun. 1987.955.

5. Nakajima. M.: Waner. J. C.: Anselme. J. P. Tetrahedron lett $1984,25.2619$

6. Chang, S. K.: I Irrington, C. W. Rothstein, M.: Shergalis, W. A.: Swern, D.: Vohra, S. K. Camer Res. 1979. 39. 387l.

7. Makhowa. N. N.: Karpow. G. A.: Mikhailyuk. A. N.: Bowa. A. E.: Khmel nitshii. L. I.: Novikor. S. S. Izv thad Kawk SSSR Se? Khim. 1978. 1. 226

8. (a) 7oltigol, M. A. Synth. Commm. 1949. 29, 905. (b) 7oltigol. M. $\Lambda$. Ghacmi. F.: Madrakian, F.: Kiany-Borazjani, M. Symth. Commm. 2000, 30, 2057. (c) 7oltigol. M. A. Shirini, $\Gamma$.. Ghorbani Choghamarani. A.: Taqian-Nasab. A.: Keypour. H.: Salehzadeh. S. J. (hem. Researchs, 2000. 420. and relerences cited therein.

9. (a) 7.oltigol. M. A.: Nematollahi. D.: Mallakpour. S. F. Simh. Commm 1999. 29, 2277. (b) 7.oltigol. M. A.: Mallakpour. S. F.: Symth. Commm 1999. 29, 4061. (c) 7oltigol. M. A.: KianyBorazjani. M.: Sadeghi. M. M.: Mohammadpoor-Baltork. I.: Memarian. H. R. Sinth Common 2000. 30. 551 . (d) Zollicol. M. A. Simh commun 2000. 30.1593 , (e) Lolngol. M. A.: Ghami. Г..: Madrakian. F. Sinth. Common. 2000. 30, 1689. (t) 7oltigol. M. A.: Mallakpour, S. F.. Madrakian. F.: Ghacmi. F. Indicm $J$. Chem. 2000. 39B, 308. (g) 7olfigol, M. A.: Kiany-Borazjani. M.: Sadeghi. M. M.: Memarian. H. R.: Moliammadpoor-Baltork. I. J. (Wem. Researchs' 2000. 167. (h) Zolligol. M. A.: KianyBorazjani. M.: Sadeghi. M. M.: Memarian. H. R.: MohammadpoorBaltork, I. Sinth. Common, 2000, 30, 2945. (i) 7olfigol. M. A.: Kiany-Borazjani, M.: Mallakpour, S. Г.: Nassi-Istahlani. H. Sumh. Commen. 2000, 30. 257.3. (j) 7oltigol, M. A.: Kiany-Boraziani. M.: Sadechi. M. M.: Mohammadpoor-Baltork. 1.: Memarian. H. R. Sinhth (ommun 2000. 30.3919.

10. Barlon. S. D.: Ollis. W. D. Comprehensive Organic (hemistm: Perganot Press: 1968: Vol. 2. pp 363-370.

11. Tumbull. K.J. Heterevel. Chem. 1985, 22,965

12. (a) Kevpour. II.: Pritchard. R. G.: Parish. R. V. Tromsition I/et (hem 1998. 23. 609. (b) Keypour. H.: Pritclard. R. G.: Parishl. R. V. Transition Met Chem 1998. 23. 121. (c) Keypour. H.: Sulehzadeh. S. Transition het Chem. 2000. 25. 205.

13. Keypour. I.: Salchzadeh, S.: Pritchard, R. G.: Parish. R. V. Inomg. Chem. 2000. 39. 5787

14. Fillison, M. K.: Schul7. C. F.: Scheidt, W. R. Inorg Chem 2000. 39.5102 .

15. Richter-Addo. G. B. lcc. (hem. Res 1999. 32. 52\% 